\title{
Experimental Research Using the 3D Printing Technology with Plastic Materials for Prehension Systems J aws
}

\begin{abstract}
ADRIAN POPESCU ${ }^{1 *}$, GEORGE ENCIU ${ }^{1}$, TIBERIU DOBRESCU ${ }^{1}$, NICOLETA ELISABETA PASCU ${ }^{2}$
'University Politehnica of Bucharest, Department of Machine and Manufacturing Systems, 313 Splaiul Independentei, 060042, Bucharest, Romania

2University Politehnica of Bucharest, Department of Engineering Graphics and Industrial Design, 313 Splaiul Independentei, 060042, Bucharest, Romania

The studies presented in this article are based on the variation of some constructive parameters on various types of materials for a prehension system jaws. The pneumatic actuation prehension system is part of the structure of a manipulator integrated within a teaching platform for installation. In the tests, the varied parameters were the following: the type of plastic material, the way of printing on the $3 \mathrm{D}$ printer bed, the degree of fill (the density) and the geometric shape. The experimental tests have resulted in an optimal version of the prehension system jaws.
\end{abstract}

\begin{abstract}
Keywords: 3D printing, prehension system jaws, Poly Lactic Acid, Acrilonitril-Butadien-Styren, Polyethylene terephthalate
\end{abstract}

The use of plastic components in the technical systems is an inexpensive and easy to develop solution in terms of employing the 3D printing technology. This technology allows the replacement of auxiliary operations such as the transport of the parts/w orkpieces to be made between different operations, the making of SDVs etc. [1-3].

For this purpose, the metallic jaws of a prehension system specific to a manipulator integrated in a didactic platform (fig. 1a) were replaced with plastic jaws obtained by the 3D printing technology (fig. 1b). The didactic platform consists of the following subassemblies: 3 gravity housings, one conveyor, a two pneumatically driven translational axes manipulator, a three-axis manipulator (one rotation axis and two translation axes) with electric drive and a prehension system with pneumatic actuation, a lid storage, a pressing system and a final assembly storage system.

The 3-axis manipulator operation cyclogram for which the prehension system whose jaws were obtained by the 3D printing technology will be tested, is shown in figure 2.

A full cycle of operation contains a total of 3 compressions of the prehension system.

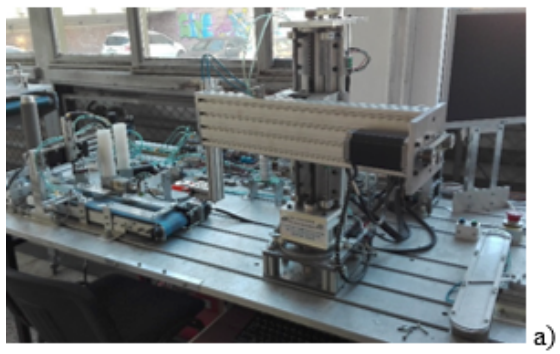

Fig. 1. The didactic platform (a) and the prehension system used for testing the jaws (b)

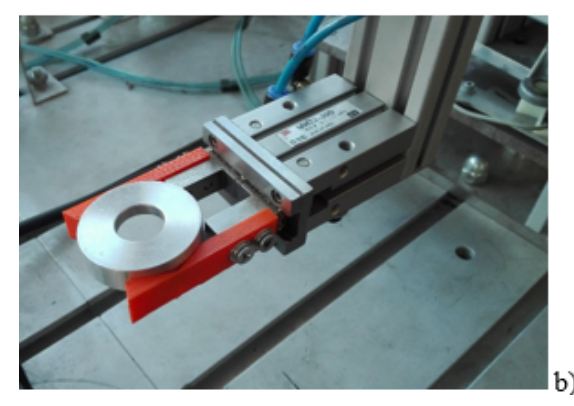

* Phone: $(+40) 214029100$

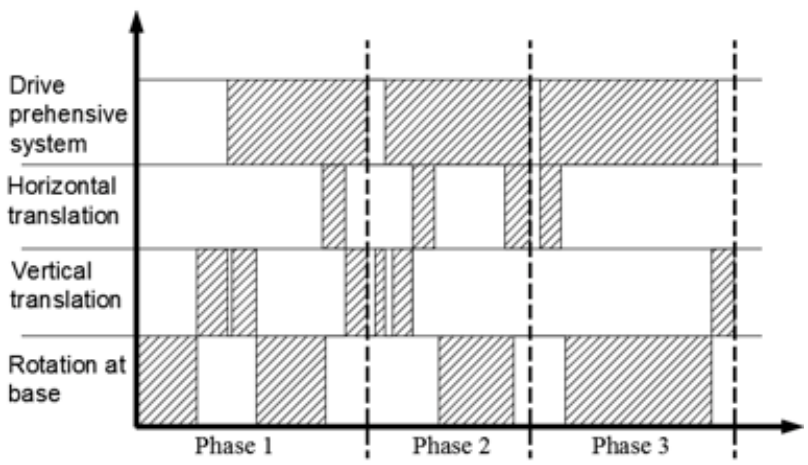

Fig. 2. The 3-axis manipulator operation cyclogram

\section{Experimental part}

Materials and methods

In order to determine the optimal constructive variant for the jaws, we designed and made jaws for which the following parameters were varied: the printing material, the printing position, the fill rate and the geometry of the part/workpiece.

The jaws were obtained on a 3D printer with the following characteristics: working space on the $X$ axis $200 \mathrm{~mm}$, on the $Y$ axis - $200 \mathrm{~mm}$, and on the $Z$ axis - 160 $\mathrm{mm}$; maximum speed on the $X$ axis - $1800 \mathrm{~mm} / \mathrm{min}$, on the $Y$ axis - $1800 \mathrm{~mm} / \mathrm{min}$, and on the Z axis - $1200 \mathrm{~mm} /$ $\min [4]$. The thread output diameter from the printing nozzle is of $0.3 \mathrm{~mm}$. The software used to generate the machine code is Simplify 3D [5].

The materials used for the experimental part were limited to: Poly Lactic Acid (PLA), Acrylonitrile-ButadieneStyrene (ABS), Polyethylene terephthalate (PET).

The PLA filament used has the following characteristics: the filament diameter $1.75 \pm 0.10 \mathrm{~mm}$ in orange. The extrusion temperature in the experimental parts/workpieces was of $210^{\circ} \mathrm{C}$ for the nozzle temperature and of $60^{\circ} \mathrm{C}$ for the build plate temperature, while the extrusion speed was kept at $640 \mathrm{~mm} / \mathrm{min}$ [6].

The characteristics of the ABS filament are as follows: the filament diameter $1.75 \pm 0.10 \mathrm{~mm}$ in black. The extrusion temperature in the experimental parts/ workpieces was of $250^{\circ} \mathrm{C}$ for the nozzle temperature and 
of $80^{\circ} \mathrm{C}$ for the build plate temperature, while the extrusion speed was kept at $640 \mathrm{~mm} / \mathrm{min}$ [7].

The PET filament has the following characteristics: filament diameter $1.75 \pm 0.10[\mathrm{~mm}]$ in blue. The extrusion temperature in the experimental parts/workpieces was of $240^{\circ} \mathrm{C}$ for the nozzle temperature and of $80^{\circ} \mathrm{C}$ for the build plate temperature, while the extrusion speed was kept at 640 [mm/min] [8].

The fill rate for the parts/workpieces obtained after printing was set at: 20,60 and 100\% for each type of material used. The parts/workpieces were printed in two ways/modes on the platform: in vertical and horizontal position, respectivelly, according to the images in figure 3.

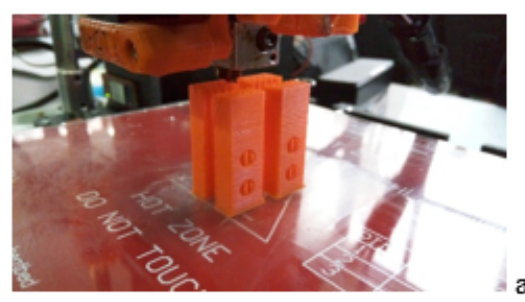

Fig. 3. Printing of jaws

a) vertical position - a

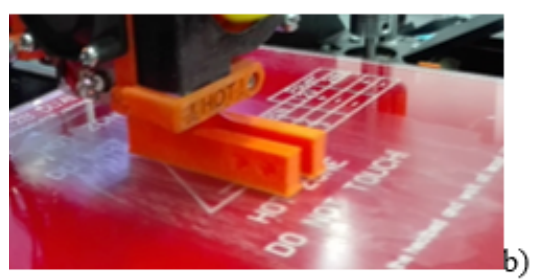

horizontal position - $b$

Table 1

CHARACTERISTICS OF THE PRINTING PROCESS

\begin{tabular}{|l|l|}
\hline Parameter & PLA, ABS, PET \\
\hline Nozzle & $0.3[\mathrm{~mm}]$ \\
\hline Layer Height & $0.2[\mathrm{~mm}]$ \\
\hline Profile & Normal \\
\hline Wall Thickness & $0.6[\mathrm{~mm}]$ \\
\hline Top/Bottom Thicknes & $0.6[\mathrm{~mm}]$ \\
\hline Infill Density & $20 \%, 60 \%, 100 \%$ \\
\hline Print Speed & $3600[\mathrm{~mm} / \mathrm{min}]$ \\
\hline Travel Speed & $4800[\mathrm{~mm} / \mathrm{min}]$ \\
\hline Support Placement & Everywhere \\
\hline Build Plate Adhesion Type & Skirt \\
\hline
\end{tabular}

\begin{tabular}{|l|l|l|l|l|}
\hline Printing Mode & $\mathrm{t}_{\mathrm{p}}$ & $\mathrm{l}_{\mathrm{f}}$ & $\mathrm{m}_{\mathrm{f}}$ & $\mathrm{cf}$ \\
\hline $20 \% / 0.5 \mathrm{~mm}$ & $26 \mathrm{~min}$ & $1526.7 \mathrm{~mm}$ & $4.59 \mathrm{~g}$ & $0.39 \mathrm{ron}$ \\
\hline $60 \% / 0.5 \mathrm{~mm}$ & $30 \mathrm{~min}$ & $2009.3 \mathrm{~mm}$ & $6.04 \mathrm{~g}$ & 0.51 ron \\
\hline $100 \% / 0.5 \mathrm{~mm}$ & $34 \mathrm{~min}$ & $2478.3 \mathrm{~mm}$ & $7.45 \mathrm{~g}$ & 0.63 ron \\
\hline $20 \% / 1 \mathrm{~mm}$ & $26 \mathrm{~min}$ & $1636.6 \mathrm{~mm}$ & $4.92 \mathrm{~g}$ & 0.42 ron \\
\hline $60 \% / 1 \mathrm{~mm}$ & $32 \mathrm{~min}$ & $2139.4 \mathrm{~mm}$ & $6.61 \mathrm{~g}$ & 0.56 ron \\
\hline $100 \% / 1 \mathrm{~mm}$ & $37 \mathrm{~min}$ & $2744.9 \mathrm{~mm}$ & $8.25 \mathrm{~g}$ & 0.7 ron \\
\hline
\end{tabular}

\begin{tabular}{|l|l|l|l|l|}
\hline Printing Mode & \multicolumn{1}{|c|}{$\mathrm{t}_{\mathrm{p}}$} & \multicolumn{1}{c|}{$\mathrm{lf}_{\mathrm{f}}$} & $\mathrm{m}_{\mathrm{f}}$ & \multicolumn{1}{c|}{$\mathrm{cf}$} \\
\hline $20 \% / 0.5 \mathrm{~mm}$ & $22 \mathrm{~min}$ & $1432.6 \mathrm{~mm}$ & $4.31 \mathrm{~g}$ & 0.34 ron \\
\hline $60 \% / 0.5 \mathrm{~mm}$ & $26 \mathrm{~min}$ & $1906 \mathrm{~mm}$ & $5.73 \mathrm{~g}$ & 0.46 ron \\
\hline $100 \% / 0.5 \mathrm{~mm}$ & $30 \mathrm{~min}$ & $2366 \mathrm{~mm}$ & $7.11 \mathrm{~g}$ & $0.57 \mathrm{ron}$ \\
\hline $20 \% / 1 \mathrm{~mm}$ & $22 \mathrm{~min}$ & $1537.5 \mathrm{~mm}$ & $4.62 \mathrm{~g}$ & 0.37 ron \\
\hline $60 \% / 1 \mathrm{~mm}$ & $27 \mathrm{~min}$ & $2085.6 \mathrm{~mm}$ & $6.28 \mathrm{~g}$ & 0.5 ron \\
\hline $100 \% / 1 \mathrm{~mm}$ & $32 \mathrm{~min}$ & $2624.5 \mathrm{~mm}$ & $7.89 \mathrm{~g}$ & 0.63 ron \\
\hline
\end{tabular}
4). During printing with a nozzle of $0.3 \mathrm{~mm}$, we were not able to obtain the thicknesses of the virtual geometric model of $0.5 \mathrm{~mm}$ and $1 \mathrm{~mm}$, respectively. Thus, the minimum actual thicknesses obtained after printing were between $0.7 \mathrm{~mm}$ and $0.8 \mathrm{~mm}$ for the minimally $0.5 \mathrm{~mm}$ thick jaws of the virtual geometric model and, respectivelly, between 1.15 and 1.2 for the minimally $1 \mathrm{~mm}$ thick jaws of the virtual geometric model.

For all the printed parts/workpieces sets, the following printing process characteristics were used (table 1).

The information on the printing time $\left(t_{0}\right)$, the length of the filament consumed $\left(l_{f}\right)$, the mass of filament consumed $\left(m_{f}\right)$ and the cost of the filament consumed $\left(c_{f}\right)$ for the jaws obtained from the three types of materials, PLA, ABS and PET printed horizontally, is presented in tables 2, 3 and 4 respectively.

Table 2 wall, a - of the virtual geometric model [9], b - made after printing
The minimum thickness of the jaws' wall was

\section{PLA JAWS PRINTING INFORMATION}


Table 4

PET JAWS PRINTING INFORMATION

\begin{tabular}{|l|l|l|c|c|}
\hline Printing Mode & $\mathrm{t}_{\mathrm{p}}$ & $\mathrm{l}_{\mathrm{f}}$ & $\mathrm{m}_{\mathrm{f}}$ & $\mathrm{cf}$ \\
\hline $20 \% / 0.5 \mathrm{~mm}$ & $25 \mathrm{~min}$ & $1500 \mathrm{~mm}$ & $4.51 \mathrm{~g}$ & $0.38 \mathrm{ron}$ \\
\hline $60 \% / 0.5 \mathrm{~mm}$ & $39 \mathrm{~min}$ & $1959.2 \mathrm{~mm}$ & $5.89 \mathrm{~g}$ & 0.5 ron \\
\hline $100 \% / 0.5 \mathrm{~mm}$ & $34 \mathrm{~min}$ & $2405.4 \mathrm{~mm}$ & $7.32 \mathrm{~g}$ & 0.61 ron \\
\hline $20 \% / 1 \mathrm{~mm}$ & $26 \mathrm{~min}$ & $1632.8 \mathrm{~mm}$ & $4.91 \mathrm{~g}$ & 0.42 ron \\
\hline $60 \% / 1 \mathrm{~mm}$ & $31 \mathrm{~min}$ & $2166.5 \mathrm{~mm}$ & $6.51 \mathrm{~g}$ & 0.55 ron \\
\hline $100 \% / 1 \mathrm{~mm}$ & $36 \mathrm{~min}$ & $2684.7 \mathrm{~mm}$ & $8.07 \mathrm{~g}$ & 0.69 ron \\
\hline
\end{tabular}

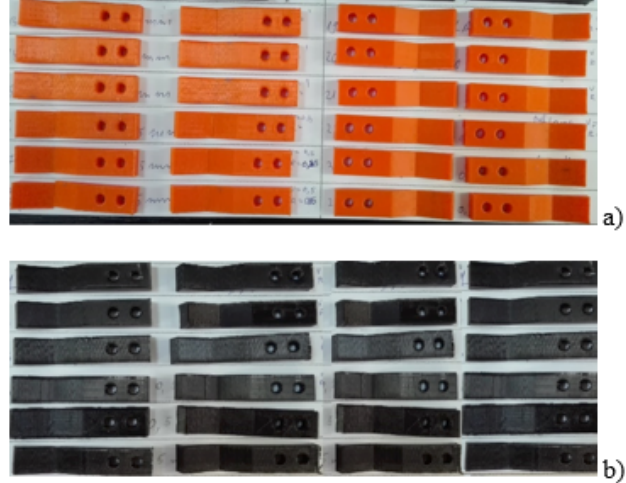

Fig. 5. PLA (a) and ABS (b) Jaws

\section{Results and discussions}

After printing the parts/workpieces in accordance with the construction parameters mentioned above, all the jaws were mounted on the pneumatic prehension system of the manipulator and subjected to repeated stresses for compressing a $39.8 \mathrm{~mm}$ diameter cylindrical piece at a pressure of 3.5 bar. Figure 5 shows the printed samples from PLA and ABS.

The tests were performed to highlight the behavior of the jaws in terms of elastic or plastic deformation [10].

The results obtained for the jaws of the three types of materials according to the constructive parameters and the number of operating cycles were centralized in table 5.

After the tests, it was found that for the PLA jaws with a $100 \%$ fill rate, the horizontal printing position and the 0.5 $\mathrm{mm}$ thickness of the virtual geometric model, following a repeated stress of 655 operation cycles, there is a plastic deformation of over $2 \mathrm{~mm}$ to normal (fig. 6. a).

The ABS jaws with a $100 \%$ fill rate, the horizontal printing position and the $0.5 \mathrm{~mm}$ thickness of the virtual geometric model, following a repeated stress of 15 operation cycles

\begin{tabular}{|l|l|l|l|}
\hline \multirow{2}{*}{ Fill rate / printing position / wall } & \multicolumn{3}{|l|}{ Number of operation cycles } \\
\cline { 2 - 4 } & PLA & ABS & PET \\
\hline $20 \% /$ horizontal $/ 0.5 \mathrm{~mm}$ & $>1200$ & $>125$ & $>1000$ \\
\hline $60 \% /$ horizontal $/ 0.5 \mathrm{~mm}$ & $>1000$ & $>120$ & $>800$ \\
\hline $100 \% /$ horizontal $/ 0.5 \mathrm{~mm}$ & $>600$ & $>100$ & $>400$ \\
\hline $20 \% /$ horizontal $/ 1 \mathrm{~mm}$ & $>3000$ & 21 & $>3000$ \\
\hline $60 \% /$ horizontal $/ 1 \mathrm{~mm}$ & $>3000$ & 20 & $>3000$ \\
\hline $100 \% /$ horizontal $/ 1 \mathrm{~mm}$ & $>3000$ & 15 & $>3000$ \\
\hline $20 \% /$ vertical $/ 0.5 \mathrm{~mm}$ & 0 & 0 & 0 \\
\hline $60 \% /$ vertical $/ 0.5 \mathrm{~mm}$ & 0 & 0 & 0 \\
\hline $100 \% /$ vertical $/ 0.5 \mathrm{~mm}$ & 0 & 0 & 0 \\
\hline $20 \% /$ vertical $/ 1 \mathrm{~mm}$ & 585 & 3 & 500 \\
\hline $60 \% /$ vertical $/ 1 \mathrm{~mm}$ & 410 & 4 & 350 \\
\hline $100 \% /$ vertical $/ 1 \mathrm{~mm}$ & 243 & 4 & 200 \\
\hline
\end{tabular}

of, were damaged (fig. 6.b). The PET jaws of the same category after 450 operation cycles were plastically deformed (fig. $6 \mathrm{c}$ ).

For each type of material, the ruptures in the minimum resistance area were highlighted. Thus, for the PLA jaws, the rupture was uniform, the plastic fibers being broken linearly (fig. 7). After the crack appeared in the jaw's minimum resistance area, the prehension system was no longer functional, it dropped the part/workpiece.

The ABS jaws broke unevenly and the material fibers broke non-linearly in the form of saw teeth (fig. 8). The rupture for this type of material occurred much faster than for the PLA.

The behavior of the PET jaws is very similar to that of the PLA jaws. The rupture produced in the jaws' minimum resistance area was linear but with small irregularities (fig. 9).

All the jaws made with the 20,60 and $100 \%$ fill rate, the vertical printing position and the $0.5 \mathrm{~mm}$ wall thickness of the virtual geometry model, deformed elastically or broke during the stresses since the first tests, and they did not permit the handle part/workpiece to be held and maintained (fig. 10).

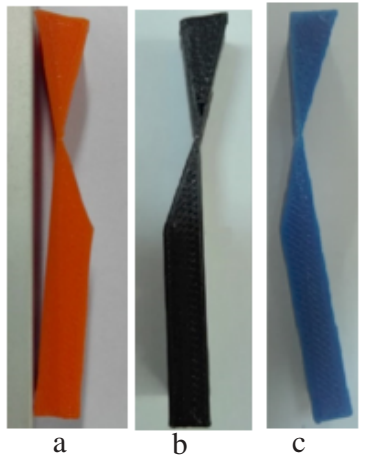

Fig. 6. Plastically deformed jaws $a$ - PLA, $b$ - ABS,

$$
c-\text { PET }
$$
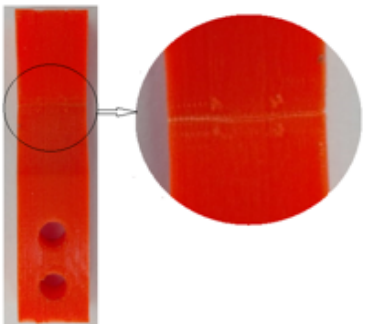

Fig. 7. Damaged PLA jaw
Table 5

NUMBER OF OPERATING CYCLES FOR EACH TYPE OF JAW 

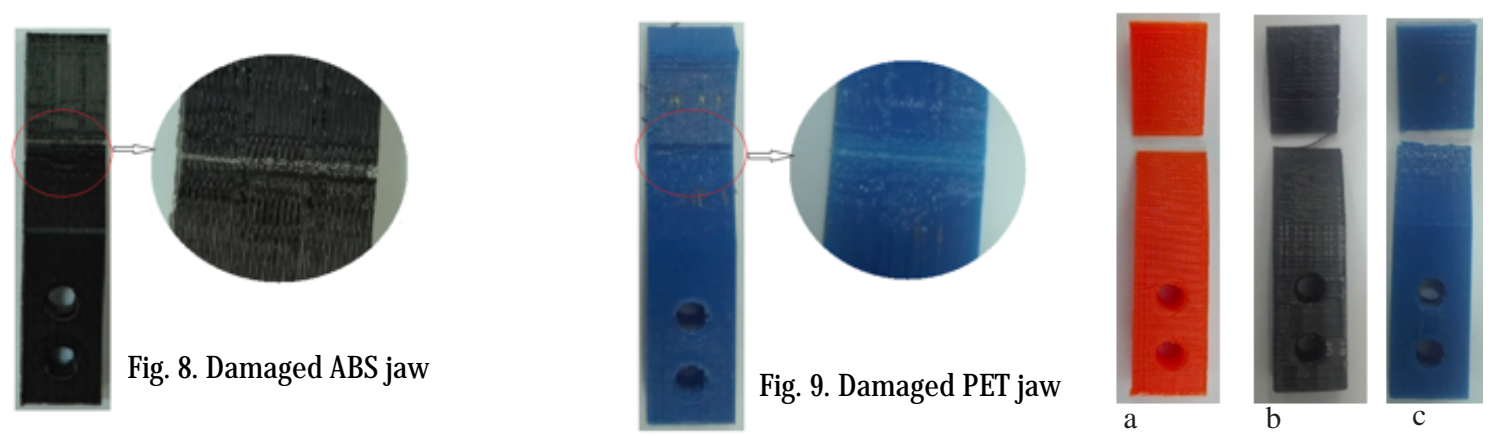

Fig. 10 Jaws broken in the

minimum

resistance area

The jaws made with the $20 \%, 60 \%$ and $100 \%$ fill rate, vertical printing position and $1 \mathrm{~mm}$ wall thickness of the virtual geometry model resisted a number of cycles ranging from 3 to 585 , the ABS being the least resistant (according to table 5).

It was found for all the jaws with the minimum programmed thickness of $0.5 \mathrm{~mm}$, that they have a higher resistance to cyclic stresses for those with a fill rate of $20 \%$ and $60 \%$ compared to those with a fill rate of $100 \%$.

For the jaws with the $1 \mathrm{~mm}$ minimum thickness of the virtual geometric model and a fill rate of $20 \%, 60 \%$ and $100 \%$ of PLA and PET, no structural modification was observed during the cyclical stresses. Wear marks occurred on the ABS after 125 cycles.

\section{Conclusions}

The article highlighted the importance of the constructive parameters for a prehension system's jaws obtained through the 3D printing technology. All vertically printed jaws, regardless of the material from which they are made, cannot be used.

The ABS jaws had the lowest resistance to cyclical stresses, of the materials used for experimental research.

After the wear occurs, the jaws do not hold the part/ workpiece well enough for it to be safely handled.

As a conclusion of this study, by comparison and taking into account the values presented in tables 2, 3, 4 and 5, the optimal constructively and economically variant was the PLA jaw with the minimum programmed wall thickness of $1 \mathrm{~mm}$ and horizontal printing mode.

\section{References}

1. PASCU, N. E., ARION, A.F., DOBRESCU, T., CARUTASU, N.L., Fused Deposition Modeling Design Rules for Plastics, Mat. Plast., 52, no. 2, 2015, p. 141

2. VALTER, N., ANDRONICEANU, A., DRAGULANESCU, I.V., DUCA M., Agile Management Based on Modularization of Products and Processes, Proceedings of BASIQ, Basiq International Conference: New Trends in Sustainable Business and Consumption, June 02-03, Konstanz, Germany, p. 310-318, 2016

3. POPESCU, D., HADAR, A., COTET, C., Manufacturing of ABS P400 Solid Cellular Structures with Closed Cells By Fused Deposition Modeling as Rapid Prototyping Process, Mat. Plast., 43 , no. 2, 20106, p. 175

4. ${ }^{* * *}$ Available at: https://shop.prusa3d.com/en/17-3d-printers 5.*** Simplify3D Technical Specifications, available at: http:// www.simplify3d.com

6. ***Available at: https://shop.prusa3d.com/en/21-pla

7. $* * *$ Available at: https://shop.prusa3d.com/en/19-abs

8. ***Available at: https://shop.prusa3d.com/en/23-pet

9. ARION, A., DOBRESCU, T.G., PASCU, N.E., 3D Surface Modelling Aspects for 3D Printing, Proceedings in Manufacturing Systems, Volume 9, Issue 4, Editura Academiei Romane, Bucuresti, p. 199-204, 2014 10. CARUTASU, N.L., SIMION, I., CARUTASU, G., J IGA, G., ARION, A.F., Experimental Test for Elastic and Mechanical Evaluation of ABSPlastic Used in 3D Printing, Mat. Plast., 52, no. 3, 2015, p. 397

Manuscript received: 21.11 .2017 